\section{Are Decentralized Pharmacy Services the Preferred Model of Pharmacy Service Delivery within a Hospital?}

\section{THE "PRO" SIDE}

For the purposes of this article, the term "decentralized pharmacy services" is considered to refer to a practice model in which a pharmacist located on the ward is responsible for both clinical and distribution services, including order validation and possibly order entry. We believe that such decentralized pharmacy services are the preferred method of pharmacy service delivery in a hospital because of the following advantages: increased patient safety, increased efficiency in patient care, cost-effectiveness, and increased job satisfaction for both pharmacists and other members of the health care team.

In Canada, nearly half of hospitals (44\%-46\%) are currently utilizing a decentralized practice model, with only $7 \%$ using a strictly centralized pharmacy practice model, in which clinical pharmacists have few to no distributive responsibilities. ${ }^{1}$ Clinical pharmacists have been shown to improve both morbidity- and mortality-related outcomes for patients by providing drug-use evaluation, in-service education, management of adverse drug reactions, management of drug protocols, and admission and discharge medication reconciliation, as well as by participating on cardiopulmonary resuscitation teams and medical rounds and contributing in various ways to reducing the length of the hospital stay. ${ }^{2-4}$ There is no denying that increasing the number of pharmacists who provide direct patient care will improve patients' outcomes. ${ }^{3}$ However, to our knowledge, it does not appear that pharmacists have to be providing clinical services $100 \%$ of the time to achieve these outcomes. ${ }^{3}$

First, a decentralized pharmacy service model has the potential to improve patient safety. One study specifically evaluated the impact of a decentralized service in a pediatric intensive care unit (ICU). ${ }^{5}$ After implementation of the decentralized service, clinical pharmacists were able to complete more interventions (69\% before implementation versus $91 \%$ after implementation), and the number of pharmacist interventions per prescription decreased ( 0.17 before versus 0.12 after, $p=0.03$ ). The authors suggested that more problems were solved on the ward before the prescription was entered into the pharmacy system. An independent expert panel reviewed the interventions and found no increase in detrimental errors with this practice change. ${ }^{5}$ Poor communica- tion between health care providers is the underlying factor in the majority of medical errors, including those that involve medication. ${ }^{6}$ Improved communication with the ward pharmacist for both clinical and distribution-related tasks may decrease the risk of medication errors. It has been recognized that "nurses like the model because there is only one 'go-to' pharmacist for their medication needs."7 In addition, Lorimer and others ${ }^{8}$ reported that the ability to speak face to face and discuss issues on the ward improved communication within the team.

Second, implementing decentralized pharmacy services has the potential to improve efficiency in patient care. In the pediatric ICU study, having a clinical pharmacist on site, from the time each order was initiated, substantially reduced unnecessary phone calls, minimized delays in getting medications to the patients, and improved prescription turnaround time. ${ }^{5}$ The clinical pharmacist entered and validated orders $3.5 \mathrm{~h} / \mathrm{day}$, and no decrease in clinical activities or patient follow-up was observed. ${ }^{5}$ In conjunction with entering orders, the pharmacist was still able to visit patients, educate residents, and answer questions as part of his/her clinical job. The number of patients followed per day increased (from 8.9 to $10.9, p=0.05$ ), as did the proportion of information requests answered by the clinical pharmacist (from $82 \%$ to $95 \%$, $p=0.09) .5$ In a decentralized model, orders can be validated by a pharmacist who practises comfortably in the clinical area, is familiar with evidence-based practice for that particular patient population, and has a well-established relationship with patients and other health care professionals.

Third, decentralized pharmacy models have been shown to be cost-effective. Lorimer and others ${ }^{8}$ reported expansion of clinical pharmacist coverage from $20 \%$ to $100 \%$ of wards using a decentralized model without an increase in the number of full-time employees. In another Canadian hospital, $\$ 1.85$ per prescription was saved when $32 \%$ of the ICU prescriptions were entered and validated by the clinical ICU pharmacist. ${ }^{5}$ Extrapolating these cost savings to the entire 452-bed hospital translated into an annual cost saving of $\$ 11911$ for the pharmacy. ${ }^{5}$ Such savings have not been achieved with a centralized pharmacy services model.

Fourth, pharmacists' job satisfaction can be improved through a decentralized pharmacy model. With the extension of pharmacist training, including more residencies and the availability of entry-to-practice Doctor of Pharmacy programs, there is the potential that job satisfaction will decline within a centralized 
model, where pharmacists are unable to consistently apply their skills and knowledge and have few opportunities for growth. ${ }^{7}$ Decentralization of pharmacy services has resulted in pharmacists feeling they have a higher degree of individual accountability (one pharmacist responsible for all aspects of patient care), has created a more cohesive team environment in which all members were encouraged to advance their skills and practice, and has offered the ability to integrate clinical and operational aspects of care. ${ }^{7}$ Individuals who are empowered have better organizational commitment, which is a significant predictor of job turnover. ${ }^{9}$ Providing opportunities for pharmacists to utilize their full scope of practice and empowering them to use all of their skills and knowledge may lead to improvements in staff turnover and retention rates. The job satisfaction of other health care professionals may also be increased with a decentralized model. In one survey conducted after implementation of a decentralized model of pharmacy services, $100 \%$ of nurses were satisfied with the change. ${ }^{5}$

In conclusion, a decentralized pharmacy service model has proven to be feasible, efficient, and cost-effective. ${ }^{5,8}$ Pharmacists and other health care professionals can have improved job satisfaction as a result of changing to this model, and patients can receive safer and more efficient care. ${ }^{5,7}$ In addition to the benefits discussed above, a decentralized pharmacy model has the potential to meet all of the goals and objectives of the CSHP 2015 project of the Canadian Society of Hospital Pharmacists that apply directly to the provision of pharmacy services by pharmacists in hospitals. ${ }^{10}$ Specifically, decentralization of pharmacy services would allow objective 4.3 to be met, whereby $80 \%$ of hospitals will have at least $95 \%$ of routine medication orders reviewed for appropriateness by a pharmacist before administration of the first dose of a medication. By implementing a decentralized pharmacy practice model in Canada, we can move toward the universal vision brought forth through the Blueprint for Pharmacy initiative, to provide "optimal drug therapy outcomes for Canadians through patient-centred care."11

\section{References}

1. Bussières JF. Chapter B: Clinical pharmacy practice. In: Babich M, Bornstein C, Bussières JF, Doucette D, Hall K, Lefebvre P, et al., editors. Hospital pharmacy in Canada 2011/2012 report. Eli Lilly Canada; 2013 [cited 2014 Dec 8]. Available from: www.lillyhospitalsurvey.ca/hpc2/content/2012_ report/chapter_b\%20.pdf

2. Kaboli PJ, Hoth AB, McClimon BJ, Schnipper JL. Clinical pharmacists and inpatient medical care: a systematic review. Arch Intern Med. 2006; 166(9):955-64.

3. Bond CA, Rachl CL. Clinical pharmacy services, pharmacy staffing, and hospital mortality rates. Pharmacotherapy. 2007;27(4):481-93.

4. Makowsky MJ, Koshman SL, Midodzi WK, Tsuyuki RT. Capturing outcomes of clinical activities performed by a rounding pharmacist practicing in a team environment: the COLLABORATE study. Med Care. 2009; 47(6):642-50.

5. Nguyen BT, Lebel D, Bussières JF. Évaluation de la saisie décentralisée des ordonnances sur l'unité des soins intensifs d'un établissement pédiatrique. Can J Hosp Pharm. 2001;54(1):15-27.

6. Ferner RE, Aronson JK. Medication errors, worse than a crime. Lancet. 2000;355(9208):947-8.
7. Knoer SJ, Pastor JD 3rd, Phelps PK. Lessons learned from a pharmacy practice model change at an academic medical center. Am J Health Syst Pharm. 2010;67(21):1862-9.

8. Lorimer HJ, Lalli SL, Spina SP. Redesign of the pharmacy practice model at a tertiary care teaching hospital. Can J Hosp Pharm. 2013;66(1):28-34.

9. Kahaleh A, Gaither C. The effects of work setting on pharmacists' empowerment and organizational behaviors. Res Social Adm Pharm. 2007;3(2): 199-222.

10. Canadian Hospital Pharmacy 2015 (CSHP 2015): CSHP 2015 goals and objectives for pharmacy practice in hospitals and related healthcare settings to be achieved by 2015. Ottawa (ON): Canadian Society of Hospital Pharmacists; 2008 May [cited 2014 Dec 15]. Available from: www. cshp.ca/dms/dmsView/2_CSHP-2015-Goals-and-Objectives-Feb25\%2707-w-Appdx-rev-May\%2708.pdf

11. Blueprint for pharmacy [website]. Ottawa $(\mathrm{ON})$ : Canadian Pharmacists Association; 2015 [cited 2015 Mar 25]. Available from: www.blueprint forpharmacy.cal

\section{Marlys LeBras, BSP, ACPR \\ Anna Maruyama, BSP, MSC \\ Danielle Stacey, BSP \\ Anita Tataru, PharmD, MSc(Pharm) \\ Doctor of Pharmacy students \\ Dawn Dalen, BSP, ACPR, PharmD \\ Clinical Assistant Professor \\ Faculty of Pharmaceutical Sciences \\ The University of British Columbia \\ Vancouver, British Columbia.}

Dawn Dalen is also Pharmacy Clinical Practice Leader - Central Okanagan and Clinical Pharmacist Specialist - Emergency Medicine with the Interior Health Authority, Kelowna, British Columbia.

Competing interests: None declared.

\section{THE "CON" SIDE}

A decentralized pharmacy model, in which the pharmacist providing direct patient care divides his or her shift between distribution and clinical activities, has not proven to be significantly advantageous over a centralized pharmacy model, in which each pharmacist is responsible for only distribution or only clinical activities during his or her shift. More specifically, a decentralized model has not been shown to improve patient safety, efficiency, cost-effectiveness, effectiveness, interprofessional collaboration, or job satisfaction. It is therefore not the preferred method of pharmacy service delivery within a hospital.

\section{Decentralized Pharmacy Service May Negatively Affect Patient Safety}

Current evidence for decentralized pharmacy models either did not have patient safety as an outcome ${ }^{1}$ or is descriptive. ${ }^{2}$ Having the same pharmacist recommending and verifying medication orders increases the possibility of an error being overlooked through absence of objective verification. Decentralization forces the pharmacist to undertake distractive multitasking and taskswitching numerous times throughout the day. Such interruptions in duties may increase the risk of error and harm to the patient relative to a centralized pharmacy model. 


\section{Decentralized Pharmacy Service Is Not More Efficient than a Centralized Model}

A decentralized model creates many inefficiencies and redundancies. Managing distribution-related issues (e.g., change of formulation, order entry error, in-stock and back-order status) takes time away from the performance of direct patient care activities. More important, there is a redundancy in maintaining 2 service models concurrently—when the decentralized service ends for the day, order processing reverts to a centralized model.

A model whereby the clinical pharmacist verifies orders from anywhere in the hospital is often difficult to implement. In many hospitals, pharmacy documentation is still paper-based, and the technology required for hospital-wide order verification may be lacking. Moreover, decentralization does not accommodate pharmacists whose practice is not ward-based (e.g., infectious diseases consult team). In a decentralized model, consult pharmacists would be required to move around the hospital to verify orders, or the ward pharmacist would have to verify orders for patients not under his or her care.

The centralized model utilizes the principles of specialization and division of labour, whereby each individual is dedicated to a specific role within a team focused on a common goal. This approach is used in health care as a whole, with specialized health care professionals and specialized physicians. Having dedicated pharmacists assigned to either a clinical or distributional role for the entirety of their shifts utilizes specialization and division of labour to increase the effectiveness of the system. Patient care is delivered more effectively.

\section{Decentralized Pharmacy Service Is Not More Cost-Effective}

Nesbit and others ${ }^{3}$ analyzed the economic benefit of having an integrated pharmacist on the health care team. The pharmacist was able to focus on direct patient care while pharmacists in a satellite or central pharmacy fulfilled distribution duties. Over a 12-month period, the academic tertiary care centre realized cost savings of $\$ 392000 .{ }^{3}$ Nguyen and others ${ }^{1}$ found that the workload of a dispensary pharmacist could be reduced by $2 \mathrm{~h} /$ day and \$11 911 could be saved annually with a decentralized model. However, the decentralized clinical pharmacist spent $3.5 \mathrm{~h} /$ day verifying orders, which could lead to a decreased cost savings overall, as there would be less time to make clinically important interventions. ${ }^{1}$

\section{Decentralized Pharmacy Service Is Not More Effective}

One argument for improved effectiveness stems from a pilot project assessing a number of outcomes before and after implementation of a decentralized model in a 24-bed pediatric intensive care unit. ${ }^{1}$ The authors defined an intervention as any action taken after a medication order was written. They reported an increase in interventions undertaken by the decentralized clinical pharmacist and found a statistically significant reduction in the number of interventions per prescription by any pharmacist. The authors postulated that this reduction could be attributed to problems being solved on the ward, before the prescription was entered into the pharmacy system, but they did not document any interventions performed before the order was written. On the basis of these results, it is not possible to determine why there was a reduction in interventions. For example, the reduction might be the result of a reduction in the total number of prescriptions in the decentralized phase of the study. Furthermore, the clinical pharmacist was removed from clinical responsibilities for $3.5 \mathrm{~h} /$ day, which could also lead to a reduction in interventions. The hypothesis that employing a decentralized model leads to increased effectiveness of clinical pharmacy delivery is not strongly supported by this evidence.

Having pharmacists provide direct patient care (clinical services) $100 \%$ of the time results in improved patient outcomes, including meeting goals for evidence-based outcomes and reducing 3-month readmission rates. ${ }^{4}$ Pharmacists may not be able to deliver the care needed to generate these outcomes if they are required to split their time between direct patient care activities and distribution responsibilities.

\section{Decentralized Pharmacy Service Reduces Collaboration with Other Health Care Professionals}

Part of the decentralized pharmacist's time would be dedicated to distribution activities, reducing time for interactions with other health care professionals. Many members of the health care team are still not aware of the pharmacist's role within the team. ${ }^{5}$ Focusing on distribution activities on the ward perpetuates the image that pharmacists are merely drug dispensers. Haas and others ${ }^{6}$ commented that a unit-based model, which is reflective of a decentralized pharmacy model, leads to less integration of the clinical pharmacist into interprofessional teams.

\section{Decentralized Pharmacy Service Does Not Increase Job Satisfaction}

Kerschen and others ${ }^{7}$ demonstrated that job satisfaction increased with increasing time spent engaging in direct patient care activities. A centralized model would allow pharmacists to maximize their time participating in such activities.

In contrast, a decentralized model would prevent pharmacists from spending time with patients during the time required to fulfill distribution duties. The inability to fully dedicate their time to performing clinical activities may compromise job satisfaction. It would be better to have pharmacists rotate through the clinical and distributional roles, focusing on only one role during each shift.

\section{Conclusion}

Decentralized pharmacy services have not been demonstrated to significantly improve patient safety, efficiency, cost-effectiveness, effectiveness, interprofessional collaboration, or job satisfaction over a centralized pharmacy services model. 
References

1. Nguyen BT, Lebel D, Bussières J. Évaluation de la saisie décentralisée des ordonnances sur l'unité des soins intensifs d'un établissement pédiatrique. Can J Hosp Pharm. 2001;54(1):15-27.

2. Lorimer HJ, Lalli SL, Spina SP. Redesign of the pharmacy practice model at a tertiary care teaching hospital. Can J Hosp Pharm. 2013;66(1):28-34.

3. Nesbit TW, Shermock KM, Bobek MB, Capozzi DL, Flores PA, Leonard MC, et al. Implementation and pharmacoeconomic analysis of a clinical staff pharmacist practice model. Am J Health Syst Pharm. 2001;58(9):784-90.

4. Makowsky MJ, Koshman SL, Midodzi WK, Tsuyuki RT. Capturing outcomes of clinical activities performed by a rounding pharmacist practicing in a team environment: the COLLABORATE study. Med Care. 2009;47(6):642-50.

5. Makowsky MJ, Schindel TJ, Rosenthal M, Campbell K, Tsuyuki RT, Madill HM. Collaboration between pharmacists, physicians and nurse practitioners: a qualitative investigation of working relationships in the inpatient medical setting. J Interprof Care. 2009;23(2):169-84

6. American College of Clinical Pharmacy; Haas CE, Eckel S, Arif S, Beringer PM, Blake EW, Lardieri AB, et al. Acute care clinical pharmacy practice : unitversus service-based models. Pharmacotherapy. 2012;32(2):e35-44.

7. Kerschen AM, Armstrong EP, Hillman TN. Job satisfaction among staff, clinical, and integrated hospital pharmacists. J Pharm Pract. 2006;19(5):306-12.
Megan Harbin, BSC(Pharm) ACPR

Timothy S Leung, BSC(Pharm) ACPR

Tamara Mihic, BSc(Pharm) ACPR

Gloria Su, BSC(Pharm) ACPR

Doctor of Pharmacy students

Sam Louie, BSc(Pharm)

Adjunct Professor

Faculty of Pharmaceutical Sciences

The University of British Columbia

Vancouver, British Columbia

Competing interests: None declared.

The Pro and Con articles for this issue's "Point Counterpoint" column were developed from a debate held in fall 2014 as part of the course "Advanced Pharmacy Administration: Topics in Contemporary Practice", Doctor of Pharmacy program, Faculty of Pharmaceutical Sciences, The University of British Columbia.

\section{CJHP Subscriptions 2015 / Abonnements au JCPH 2015}

New for 2015, we have moved to an online only version of CJHP, and have also introduced an institutional online subscription option. CJHP online is included as a benefit of CSHP membership. All prices are in Canadian funds.

En nouveauté pour 2015, nous avons migré vers la publication d’une seule version du $J C P H$, soit la copie électronique en ligne, et nous offrirons aussi en option un abonnement institutionnel. L'abonnement à la version électronique du JCPH publiée en ligne est inclus dans les droits d'adhésion à la SCPH. Tous les prix sont en dollars canadiens.

\begin{tabular}{lll}
$\begin{array}{l}\text { Subscriber group / } \\
\text { Groupe d'abonnés }\end{array}$ & $\begin{array}{l}\text { Individual Online Subscription / } \\
\text { Abonnement individuel en ligne }\end{array}$ & $\begin{array}{l}\text { NEW Institutional Online Subscriptions / } \\
\text { NOUVEL abonnement institutionnel en ligne }\end{array}$ \\
\hline $\begin{array}{l}\text { Nonmembers within Canada / } \\
\text { Non-membres au Canada }\end{array}$ & $\begin{array}{l}\text { 160.00 per year, plus GST or HST } \\
\text { 160,00 } \$ \text { par an, plus TPS ou TVH }\end{array}$ & $\begin{array}{l}\text { \$480.00 per year, plus GST or HST } \\
480,00 \text { \$ par an, plus TPS ou TVH }\end{array}$ \\
\hline USA / É.U. & $\$ 190.00$ per year & $\$ 510.00$ per year \\
& $190,00 \$$ par an & $510,00 \$$ par an \\
\hline Foreign / Étranger & $\$ 230.00$ per year & $\$ 550.00$ per year \\
& $230,00 \$$ par an & $550,00 \$$ par an
\end{tabular}

More details can be found at www.cjhp-online.ca. Please direct comments or questions to cjhpedit@cshp.ca.

Des détails supplémentaires sont fournis à www.cjhp-online.ca. Pour tout commentaire ou toute question, veuillez vous adresser à cjhpedit@cshp.ca. 